\title{
Editorial
}

\section{Corticosteroids for preterm deliveries: missing evidence}

Newton Opiyo, William Stones

03 May 2017

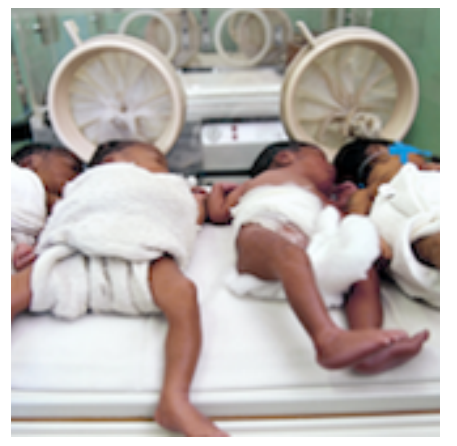

Preterm birth is a major cause of death and morbidity in babies worldwide.[1] The majority of preterm deliveries and deaths occur in Africa and Asia. Antenatal corticosteroid administration to pregnant women at high risk of preterm delivery is a proven hospital-based intervention to reduce adverse effects associated with preterm birth.[2] This intervention has significantly contributed to reductions in adverse neonatal outcomes in high-income countries.

The efficacy of antenatal corticosteroids to promote fetal lung maturation in women at risk of preterm birth was first demonstrated in a randomized trial by Liggins and Howie over four decades ago.[3] Several randomized and observational studies have since then confirmed this important effect.

The recent Cochrane Review update considers data from 30 randomized trials and includes outcomes for 7774 women and 8158 babies. [4] The quality of evidence, assessed using GRADE, was moderate. Key findings were that antenatal corticosteroid administration is associated with reductions in relative risks for perinatal death (28\%), neonatal death (31\%), respiratory distress syndrome (34\%), intraventricular haemorrhage (45\%), necrotising enterocolitis (50\%), need for mechanical ventilation (32\%), and systemic infections in the first 48 hours of life (40\%). Corticosteroids did not increase the risk of chorioamnionitis, endometritis, or maternal death. These findings are consistent with the previous version of the Cochrane Review,[5] and they support the World Health Organization (WHO) recommendation of antenatal corticosteroids for women at risk of preterm birth worldwide.[6]

Most of the studies included in the Cochrane Review were undertaken in high-resource country hospital settings with access to intensive care and other essential supportive treatments for preterm births. In these settings, the safety and effectiveness of corticosteroid therapy for reducing preterm-associated adverse effects is unequivocal, and the priority is scale-up to address remaining gaps in coverage. However, whether similar benefits are replicable in low-resource settings (where the burden of preterm births is higher, and access to neonatal intensive care is limited) remains to be demonstrated.

Findings from the ACT trial, a large multi-country cluster-randomized trial of a multifaceted intervention to increase the use of antenatal corticosteroids for preterm birth at all levels of care (community, health centre, district hospitals) in low- and middle-income countries found that the intervention increased the risk of neonatal deaths (risk ratio 1.12, 95\% confidence interval 1.02 to 1.22).[7] For every 1000 women exposed to the multifaceted intervention, an excess of 3.5 neonatal deaths occurred. The risk of maternal 
infection was similarly increased (odds ratio $1.67 ; 95 \%$ confidence interval 1.33 to 2.09 ). These findings are in sharp contrast to the positive results from trials in high-income countries. This trial was excluded from the Cochrane Review update because it was an evaluation of a strategy to scale-up steroid treatment, rather than a test of the safety and efficacy of steroids: the multifaceted implementation strategy comprised training to improve identification of women at risk of preterm birth and measures to facilitate appropriate use of steroids.

Post-hoc exploratory analysis of the ACT trial data suggested that the excess mortality could have arisen from the use of steroids in babies who were not preterm (i.e. more than 34 weeks' gestation), possibly owing to misclassification of gestational age.[8] The lack of facilities to manage preterm newborns and associated complications may also have contributed to the excess mortality, masking any potential benefit from steroids. The important finding of increased maternal sepsis associated with corticosteroid administration may reflect the very different burden of infections in low-resource settings relative to the 'evidence for no harm' that was again confirmed for the well-resourced clinical context of the trials included in the Cochrane Review update.

There is equipoise regarding the impact of antenatal corticosteroids in low-resource settings. Evidence from primary research in such settings is critically needed before we can be certain of the balance of the risks versus benefits of this intervention. A WHO multi-country randomized trial is ongoing and is expected to provide missing evidence with regard to the place of corticosteroid administration at later gestational ages. $[9,10]$ As illustrated by the questions raised from the ACT trial, studies need to be able reliably to establish gestational age so as to be fully informative, rather than relying on proxy measures such as low birthweight. It is likely that appropriate targeting of this intervention is only feasible where gestational age can be confirmed by ultrasonography, and where an appropriate range of other supportive elements of preterm care can be provided. Finally, we also need to bear in mind our continued limited understanding of the pathophysiology of preterm birth: rather than a single disease entity it represents the outcome of several different underlying processes.[11] Better understanding of these basic mechanisms will allow more specific targeting of interventions.

\section{Author information}

Newton Opiyo ${ }^{1}$, William Stones ${ }^{2}$

${ }^{1}$ Editor, Cochrane Editorial Unit, Cochrane, London, UK; nopiyo@cochrane.org ${ }^{2}$ Professor, Departments of Public Health and Obstetrics \& Gynaecology, Malawi College of Medicine, Blantyre, Malawi; Professor of Obstetrics \& Gynaecology, St George’s, University of London, UK; wstones@medcol.mw

\section{How to cite}

Newton Opiyo, William Stones. Corticosteroids for preterm deliveries: missing evidence[editorial]. Cochrane Database of Systematic Reviews 2017;(5): 10.1002/14651858.ED000121

\section{References}

1. March of Dimes, PMNCH, Save the Children, World Health Organization. Born too soon: the global action report on preterm birth. Howson CP, Kinney MV, Lawn JE, editors. Geneva: World Health Organization; 2012. Available from www.who.int/pmnch/media/news/2012/preterm_birth_report

2. Bhutta ZA, Das JK, Bahl R, Lawn JE, Salam RA, Paul VK, et al. Can available interventions end preventable deaths in mothers, newborn babies, and stillbirths, and at what cost? Lancet 2014;384:347-70. 
3. Liggins GC, Howie RN. A controlled trial of antepartum glucocorticoid treatment for prevention of the respiratory distress syndrome in premature infants. Pediatrics 1972;50(4):515-25.

www.ncbi.nlm.nih.gov/pubmed/4561295

4. Roberts D, Brown J, Medley N, Dalziel SR. Antenatal corticosteroids for accelerating fetal lung maturation for women at risk of preterm birth. Cochrane Database of Systematic Reviews 2017;3:CD004454.

doi.org/10.1002/14651858.CD004454.pub3

5. Roberts D, Dalziel S. Antenatal corticosteroids for accelerating fetal lung maturation for women at risk of preterm birth. Cochrane Database of Systematic Reviews 2006;3:CD004454.

doi.org/10.1002/14651858.CD004454.pub2

6. World Health Organization. WHO recommendations on interventions to improve preterm birth outcomes. Geneva, Switzerland: WHO; 2015. Available at

www.who.int/reproductivehealth/publications/maternal_perinatal_health/preterm-birth-guideline

7. Althabe F, Belizán JM, McClure EM, Hemingway-Foday J, Berrueta M, Mazzoni A, et al. A populationbased, multifaceted strategy to implement antenatal corticosteroid treatment versus standard care for the reduction of neonatal mortality due to preterm birth in low-income and middle-income countries: the ACT cluster-randomised trial. Lancet 2015;385:629-39. doi.org/10.1016/S0140-6736(14)61651-2

8. Althabe F, Thorsten V, Klein K, McClure EM, Hibberd PL, Goldenberg RL, et al. The Antenatal Corticosteroids Trial (ACT)'s explanations for neonatal mortality - a secondary analysis. Reproductive Health 2016;13:62. doi.org/10.1186/s12978-016-0175-3

9. HRP. The WHO ACTION-I (Antenatal CorTicosteroids for Improving Outcomes in preterm Newborns) Trial. who.int/reproductivehealth/projects/ACTION-I.pdf (accessed 20 March 2017).

10. HRP. The WHO ACTION-II (Antenatal CorTicosteroids for Improving Outcomes in preterm Newborns) Trial. who.int/reproductivehealth/projects/ACTION-II.pdf (accessed 20 March 2017).

11. Barros FC, Papageorghiou AT, Victora CG, Noble JA, Pang R, lams J, et al. The distribution of clinical phenotypes of preterm birth syndrome: implications for prevention. JAMA Pediatrics 2015;169(3):220-9. doi.org/10.1001/jamapediatrics.2014.3040

\section{Declarations of interest}

The authors have completed the ICMJE form for disclosure of potential conflicts of interest (form available upon request) and declare that they have no conflicts of interest.

\section{Provenance and peer review}

This editorial was commissioned and was not externally peer reviewed.

\section{Image credit}

Roger Job/Reporters/Science Photo Library

\section{Keywords}

Pregnancy \& childbirth 
Devender Roberts, Julie Brown, Nancy Medley, Stuart R Dalziel

\section{Feedback}

To comment on this editorial or to propose ideas for future editorials please contact the Cochrane Editorial Unit (ceu@cochrane.org).

\section{Publications}

\section{Community}

\section{Contact Us}

\section{WILEY}

Help \& Support

About Us

Cookies \& Privacy

Wiley Job Network

Terms \& Conditions

Advertisers \& Agents 